\title{
PATTERNS OF INTRASPECIFIC VARIATION IN ANGIOSPERMS
}

\author{
R. OrNduff
}

\author{
Department of Botany, University of California, Berkeley, Calif.
}

The three papers that follow were presented in a symposium sponsored jointly by the American Society of Plant Taxonomists and the Systematic Section of the Botanical Society of America at the 1965 meeting of the American Institute of Biological Sciences held at Urbana, Illinois. A chief motive for selecting the theme of the symposium was to provide a demonstration that modern systematists are concerned not only with the taxonomic application of information concerning organisms, but that they function also as active researchers who obtain this information about the organisms with which they work. Moreover, the results of systematic research have often stimulated further investigation by workers of various allegiances, many of whom are unaware of their dependence on systematics. Much of the fundamental knowledge in such diverse fields as cytogenetics, autecology, morphology, anatomy, and even some areas of biochemistry owes its existence directly or indirectly to systematics.

Secondly, it is now clear from a number of detailed studies that many features which taxonomists have held to be a priori criteria of interspecific distinctness are in fact widespread within entities that must on practical grounds be considered single species. The paper by Mosquin serves to illustrate this point, using examples from Onagraceae. Thirdly, many of the patterns of intraspecific (as well as interspecific) variation that are so familiar to taxonomists are related to adaptations of the plant to different environments throughout its range. Although not all variation patterns can be explained on an adaptive basis, some of the most subtle morphological differences that would seem to be unrelated to the ability of a plant to survive in its habitat do in fact have a physiological importance to the plant. Björkman discusses photosynthesis and respiration in shade- and sun-inhabiting races of the Furopean goldenrod Solidago virgaurea. Although Björkman is not a systematist, his work provides an interesting example of a physiological "follow-up" of an ecological variation pattern long familiar to European botanists. The ecological approach to studying variation patterns in plants is clearly one that should be further exploited by systematic botanists. Finally, the contribution by Brehm demonstrates that the variation patterns of biochemical compounds in plants may show striking parallelisms with the variation patterns of morphological characters within or between taxa. In some instances these compounds may show considerable inter- or intraspecific variation; in others they show no variation at all. The utility of such characters, like the utility of all characters with which a taxonomist works, depends on the degree to which these characters are correlated with other phenetic traits of plants.

The emphasis of the symposium has been on intraspecific relationships, but the principles discussed by the speakers are of obvious relevance to studies at higher taxonomic levels. In the time allotted for the symposium it was impossible to present a comprehensive multidisciplinary discussion of intraspecific variation, but it is clear that many of the observations and conclusions made by the participants are of broad application in systematies.-Robert Ornduff (Convener), Department of Botany, University of California, Berkeley.

Brittonia 18: 193. Jul-Sep 1966.

[BRittonia for April--June, 1966 (18: 97-192) was issued July 13, 1966] 